\title{
UNA APORTACIÓN AL ESTUDIO DE LAS GERMANÍAS VALENCIANAS: EL SACO DE ORIHUELA DE 1521
}

\author{
Antonio CARRASCO RODRÍGUEZ \\ Universidad de Alicante
}

\begin{abstract}
Resumen
E1 30 de agosto de 1521 tuvo lugar la batalla del Rincón de Bonanza. Las tropas reales-nobiliarias dirigidas por el gobernador D. Pedro Maza y por el marqués de los Vélez infligieron una severa derrota a las milicias agermanadas, acabando así con la revuelta en Orihuela. Acto seguido, el citado marqués, pese a la oposición del gobernador, decidió entrar en la ciudad del Bajo Segura e iniciar un devastador saqueo que se prolongó durante 30 días. El presente artículo relata las incidencias más destacadas del Saco, y trata de arrojar nuevas luces sobre sus causas y sus consecuencias.
\end{abstract}

\begin{abstract}
On August 30th 1521 the battle of Rincón de Bonanza took place. The royal-nobility troops directed by the governer Pedro Maza and by the marcuis of Velez, inflicted a serious defeat on the agermandas soldiery, finishing with the riot in Orihuela. After that, the aforementioned marquis, against the oposition of the governator, decided to go into the Low Segura eity and start a devastating sacking extended over 30 days. This article relates the most relevant incidents during the sacking and tries to make clear the causes and its consequences.
\end{abstract}

Tras unos años de gran inestabilidad dentro de la diócesis de Cartagena, a la cual pertenecía la Gobernación del Reino de Valencia más allá de Jijona, el 13 de mayo de 1510 , Julio II decretó, a instancias de Fernando el Católico, la división del obispado de Cartagena, la creación del de Orihuela y su unión canónica al primero bajo la fórmula «sub uno pastore», de modo que ambas Iglesias fueron adscritas al gobierno y la administración de un mismo obispo «Carthaginensis et Oriolensis»'.

1. La bula de la creación del obispado de Orihuela se halla en A.C.O. Armario IX, Legajo III, siglo XVI, pergamino $n^{\circ} 46$. No hemos hallado, en cambio, la bula original de la unión de los obispados de Orihuela y Cartagena. Únicamente podemos hacer referencia a algunas copias de dicho rescripto. En el A.C.O. 
La disposición pontificia no cayó muy bien en Murcia, ciudad en la que se hallaba la sede episcopal cartaginense. Por ello, de inmediato, sus autoridades civiles y eclesiásticas comenzaron a suplicar tanto ante el monarca español como ante el sumo pontífice su anulación. Y aunque tenían muy bien encaminadas sus importunaciones, cometieron el error de intentar conseguir de hecho, antes que de derecho, la vuelta de la diócesis de Orihuela a la obediencia del obispo, D. Mateo Lang, y del cabildo de Cartagena. En fin, trataron de presionar a la población de la parte meridional del citado Reino de Valencia para que volviesen a reconocer su superioridad, y lo hicieron utilizando medios muy poco legítimos.

Por una parte, las referidas autoridades murciano-cartaginenses, movidas por la enemistad y el odio que sentían hacia los habitantes de Orihuela y de la Vega Baja del Segura, pusieron en práctica un terrible plan. Mandaron cavar un "riacho», esto es, una especie de cauce alternativo para el río, y consiguieron desviar su curso e inundar los campos y las heredades de los vecinos de la citada ciudad y su distrito, causando algunas muertes y la ruina de la práctica totalidad de los cultivos ${ }^{2}$.

Y por otra, trataron de convencerles de una forma menos rebuscada, simplemente por la fuerza. A principios de 1514, más de un millar de murcianos efectuaron varias incursiones por las tierras de la Gobernación, e intentaron invadir tanto la ciudad de Orihuela como su término, provocando que todo el Reino de Valencia se levantara en armas contra ellos, y causando nuevos daños a sus maltrechos habitantes ${ }^{3}$.

La violenta actitud y los medios extrajudiciales murcianos molestaron a Fernando $\mathrm{V}$ y a León X -el sucesor de Julio II en la Cátedra de San Pedro- ${ }^{4}$, y teniendo en cuenta que la voluntad de los dos soberanos coincidía en el punto de procurar la pacificación de las tierras del sudeste peninsular, podemos afirmar que fueron la causa principal de que el 27 de junio de 1515 , el referido pontífice confirmase la creación del obispado de Orihuela 5 .

La ratificación pontificia no desanimó a los murcianos. Muy al contrario, incrementaron sus gestiones en las cortes real y pontificia y, una vez fallecido el Rey Católico, con el apoyo de su nieto Carlos I lograron que León X mudase de opinión, y que el 17 de marzo de 1518 promulgase, por medio de un breve, la revocación de los rescriptos del 13 de mayo de 1510 y del 27 de junio de $1515^{\circ}$. De este modo, la vuelta de los escindidos a la obediencia espiritual cartaginense quedó pendiente de la ejecución del referido breve revocatorio por parte del provisor y el cabildo de Cartagena ${ }^{7}$.

Armario I, libro n ${ }^{\circ}$, ff. 34-35v. Y Armario X, libro ${ }^{\circ}$ 1094, ff. 92-92v.; libro $\mathrm{n}^{\circ} 1095$, ff. 10-10v.; y libro $n^{\circ} 1111$, ff. 52-52v. También hay una copia en el A.M.O. Libro $\mathrm{n}^{\circ} 2208$, Libro de Procedimientos, 1434-1525, ff. $35 \mathrm{v} .-36 \mathrm{v}$.

2. A.M.O. Libro n 39 , Contestador de 1513-15, ff. 115-115v, y 207-208. Y libro n ${ }^{\circ} 39 \mathrm{~A}$, Contestador de 1516-1517, ff. 415-417.

3. A.C.O. Armario I, libro ${ }^{\circ} 2$, ff. $272 \mathrm{v} .-273$.

4. CAPPELLI, A.: Cronologia, Cronografia e Calendario Perpetuo, Milán, 1983, p. 274. Julio II murió el 21 de febrero de 1513. Y el 11 de marzo siguiente fue elegido nuevo pontífice Juan de Médicis, que escogió el nombre apostólico de León X.

5. El breve original se halla en el A.C.O. Armario IX, Legajo III, siglo XVI, pergamino $n^{\circ} 59$.

6. A.C.O. Armario IX, Legajo III, siglo XVI, pergamino $n^{\circ} 61$.

7. D. Mateo Lang, cardenal de Santo Ángel, no pisó las tierras de su diócesis ni una sola vez a lo largo de su dilatado episcopado. Por ello, al frente de la Iglesia cartaginense se hallaba su provisor y vicario general. 
En mayo de 1518 , los representantes del aludido organismo colegiado se presentaron en Orihuela con la firme intención de poner en vigor el rescripto anulatorio, pero la respuesta de los vecinos de la ciudad del Bajo Segura fue contundente. Amén de impedirles tal propósito, los capitulares fueron maltratados, vejados y encarcelados. Y no recuperaron la libertad hasta pasado un buen número de días ${ }^{8}$.

A finales del citado año 1518 hubo un nuevo enfrentamiento armado. El cabildo de Cartagena y el Concejo de Murcia solicitaron al márqués de los Vélez -capitán general del Reino encabezado por dicha ciudad- que atacase Orihuela para vengarse de las dificultades que les estaban oponiendo en el Pleito del Obispado. D. Pedro Fajardo -que así se llamaba el noble- aceptó gustoso el encargo, reunió una numerosísima milicia, y el día de Navidad sitió la población del Bajo Segura y la bombardeó sin piedad mientras se celebraban en la «Catedral» del Salvador los divinos oficios que conmemoraban el nacimiento de Jesucristo, así como el comienzo del año cristiano. Sin embargo, Orihuela, lejos de ceder al ataque de sus adversarios bélico-espirituales, reaccionó preparando una espectacular contraofensiva que obligó al marqués y a sus tropas a retirarse a Murcia, para defender la ciudad. De cualquier forma, la razia del marqués causó ingentes destrozos y pérdidas en el término oriolano -robo de animales, incendio de casas, tala de árboles, arrasamiento de los campos de cultivo-. A fin de protestar ante Carlos I, el Consell de la ciudad del Bajo Segura hizo una estimación de los daños y éstos fueron valorados en unos $; 50.000$ ducados!?

Posteriormente, en febrero de 1520, el cabildo de Cartagena trató de poner en ejecución el breve revocatorio de la creación del obispado de Orihuela, pero aunque su síndico llegó a presentar el rescripto ante el capítulo del Salvador, sus componentes perseveraron en su negativa a aceptarlo. Poco les importaban las múltiples censuras y penas eclesiásticas y pecuniarias que habían sido impuestas sobre ellos y sobre toda la ciudad. Los oriolanos no estaban dispuestos a perder lo que tanto tiempo, esfuerzo y dinero les había costado ${ }^{10}$. Y temiendo un nuevo ataque murciano y aprovechando el auge progresivo de la Germanía en la ciudad, sus autoridades, a instancias de los síndicos del pueblo y de los Trece -dirigentes del «adezenamiento»-, comenzaron a comprar armas y a mejorar las medidas defensivas y las fortificaciones ".

A partir de este momento, la «Germania sacramental» creció hasta tal punto en Orihuela que dicha población se convirtió en uno de los principales focos de rebelión.

Con el transcurso de los primeros meses de 1521, la situación en la ciudad del Bajo Segura empeoró, y los desórdenes populares adquirieron cada vez mayor magnitud.

Viendo que la Germanía adquiría posiciones cada vez más fuertes, el virrey, D. Diego Hurtado de Mendoza -conde de Mélito-, insistió a los síndicos del pueblo y a los Trece oriolanos que, siguiendo las órdenes reales, depusiesen las armas. Pero los

8. A.C.O. Armario X, libro $n^{\circ}$ 1094, ff. 118-124. A.M.O. Libro n ${ }^{\circ} 2208$, Libro de Procedimientos. 14341525. ff. 65-7lv.

9. A.M.O. Libro no 2208, Libro de Procedimientos, 1434-1525, ff. 94v., 101, 105, 107, 112v. 115v., 119-119v., 144v.-145, 150-150v.

10. A.M.O. Libro n ${ }^{\circ} 40$, Contestador de 1520, ff. 73-79v.

11. Ibidem, ff. 172-172v., 181. 
agermanados se negaron a obedecer y respondieron al máximo representante de la autoridad real en el Reino de Valencia que estaban asombrados de que les mandasen tal cosa porque necesitaban las armas para «castigar a los moros y turcos que cada día vienen a correr la costa, y otras necesidades», y porque buena parte de dichas armas no eran propiedad de las cofradías, sino que los «adecenados» las habían comprado «con sus propios dineros» y las requerían «para la deffensa de la tierra» ${ }^{12}$.

La persistencia de los agermanados oriolanos obligó al conde de Mélito a cambiar de táctica. Por ello, tras sopesar diferentes posibilidades, decidió pedir a D. Ramón de Rocafull que fuese a la ciudad del Bajo Segura a tratar de conseguir someter a los rebeldes a la autoridad real. El virrey escogió para tal misión al señor de Albatera porque, junto al gobernador D. Pedro Maza de Lizana, era el líder de los nobles y caballeros de la Gobernación, y también porque era uno de los personajes más temidos por los insurrectos. D. Ramón se personó en Orihuela e intentó convencer a los menos afectos a la Germanía. No obstante, al poco de comenzar su arriesgada misión, los síndicos del pueblo se enteraron de sus tejemanejes, «tocaron las campanas a rebato, y mientras en la plaza se reunía la gente con armas, Don Ramón de Rocafull, a uña de caballo, huyó a su solar de Albatera». Allí reunió a los caballeros refugiados para planear la mejor solución para acabar con la rebelión ${ }^{13}$.

Sin embargo, los servicios de información de los agermanados funcionaban con diligencia, y pronto los cabecillas tuvieron noticia de dicho conciliábulo. Y se plantearon dar un tremendo golpe de efecto: quemar la villa de Albatera. No obstante, cuando casi estaban preparados para salir, los partidarios de Rocafull en la ciudad consiguieron calmar los ánimos incendiarios. No pudieron evitar, empero, que los adecenados, para desquitarse, apresaran a tres afamados caballeros: Jaime Roca, Luis Togores y Andrés Soler. Aunque con posterioridad, los ayudaron a escapar, y los tres lograron llegar sanos y salvos al regufio albaterense ${ }^{14}$.

El siguiente plan de los agermanados oriolanos fue algo más razonado, pero no menos descabellado. Buscando congraciarse con el lejano Carlos I, quisieron incrementar su real patrimonio ofreciéndole nuevas tierras y bienes. Así, decidieron emancipar las villas de Elche y Crevillente del yugo de su señor, el marqués de Elche, y entregárselas directamente al rey. Y el cabecilla Pedro Palomares capitaneó las milicias populares, respaldó el levantamiento ilicitano y conquistó la vilia para la Germanía ${ }^{15}$.

Pero en lugar de ganar la voluntad de Carlos I, le hicieron tomar conciencia del gravísimo problema que constituía la revuelta, por lo que desde Alemania escribió a los distintos gremios de las poblaciones agermanadas, aconsejándoles que volviesen a la obediencia real. Así, algunas localidades tendieron a tranquilizarse, pero en otras persistió la rebeldía, y se hizo evidente que no quedaba ninguna solución pacífica para la insurrección. Ya no quedaba más remedio que vencerla por la fuerza.

12. CHIARRI MARTÍN, M.L.: Orihuela y la guerra de las Germanías, Murcia, 1963, p. 53.

13. Ibidem, pp. 60-61.

14. Ibidem, p. 61.

15. lbidem, pp. 63-64. 
De esa manera, el virrey proyectó una reunión en Gandía con los nobles y caballeros del Reino que habían de luchar contra los agermanados. De esta concentración salió D. Ramón de Rocafull con el encargo de reclutar hombres para el ejército virreinal. Al enterarse de la labor del señor de Albatera, los populares oriolanos se unieron con partidarios de Elche y, tras formar un tropel de unos 4.000 hombres, marcharon hacia la villa que servía de refugio a los nobles. La atacaron con insistencia pero la gallardía de los defensores les impidió el triunfo. Finalmente, los agermanados hubieron de desistir. Y Rocafull, con tres compañías de hombres leales, marchó al encuentro de las tropas del conde de Mélito ".

Posteriormente, la guerra comenzó, y los oriolanos de ambos bandos tuvieron una importante participación en diferentes hitos bélicos que, para no hacer demasiado prolija la narración y por no ser el objetivo central de nuestra investigación, dejamos de relatar.

De cualquier forma, señalaremos que los primeros pasos agermanados, esto es, el asalto del castillo de Játiva y la batalla de Gandía, fueron triunfales. Tras las victorias iniciales, los rebeldes se dedicaron al saqueo y al bautismo forzoso de mudéjares - con escobas y ramas mojadas en las acequias - en la citada localidad de Gandía, y también en Oliva, Vilallonga, Guadalest, Penáguila y Polop, entre otras poblaciones, buscando, al parecer, el empalme con los comuneros castellanos.

El virrey embarcó en Denia hacia Peñíscola y organizó la resistencia invocando la ayuda murciana, que jugaría un papel decisivo en el inmediato enfrentamiento militar.

Tras la derrota en Gandía y después de muchas vicisitudes, D. Pedro Maza volvió a las tierras de su Gobernación con la misión de socorrer el castillo de Orihuela, que estaba siendo asediado por los insurrectos y era defendido por unos pocos hombres capitaneados por Jaime Despuig. Y para facilitarle la tarea, D. Diego Hurtado de Mendoza mandó a Murcia al Almirante de Aragón, D. Alonso de Cardona, para que, ejerciendo toda su influencia, recabara del marqués de los Vélez ayuda para la defensa de la citada fortaleza oriolana. Del mismo modo, Maza reunió a todos sus efectivos y se dirigió al reino vecino con la intención de pedir auxilio a $\mathrm{D}$. Pedro Fajardo -el referido marqués-, quien ya estaba preparando un gran ejército ${ }^{17}$.

Los agermanados oriolanos, previendo el peligro que se les avecinaba desde el otro lado de la frontera, decidieron enviar emisarios a Játiva, en busca de apoyo urgente. También escribieron a los Trece valencianos con idéntico objetivo. Los rebeldes setabenses respondieron a los requerimientos de sus compañeros de Orihuela enviando hombres armados, e invitando a los agermanados de otras villas como Alcoy, Jijona, Onteniente, Albaida, Cocentaina o Penáguila a engrosar con milicianos las filas del ejército "popular». Los contingentes se reunieron en Alcoy bajo el mando de fr. Miguel García, capitán general de Játiva. Recogieron en Jijona al capitán Bocanegra y se dirigieron hacia la ciudad del Bajo Segura a marchas forzadas.

16. Ibidem, pp. 67-68.

17. Ibidem, pp. 74-76. 
Por su parte, en Peñíscola, el virrey estaba ocupado en trazar los planes convenientes para lograr la rendición de Murviedro y Valencia, por lo que encomendó al gobernador Maza la represión de la revuelta oriolana ${ }^{18}$.

El 27 de agosto de 1521, el ejército agermanado hizo su entrada en Orihuela. Y de inmediato, los Trece de dicha ciudad enviaron un ultimátum a Jaime Despuig: o rendía el castillo, o lo tomarían por la fuerza. Despuig se negó a abandonar la resistencia, y se preparó para hacer frente al ataque. Durante los dos días siguientes, las tropas rebeldes trataron en balde de conquistar la citada fortificación.

El día 28 D. Pedro Maza, conociendo la desesperada situación del castillo, se decidió a ayudar a Jaime Despuig. Así, dio indicaciones al marqués de los Vélez para que efectuase una maniobra de diversión en las puertas de la ciudad, a fin de enviar víveres, armas y hombres a la fortaleza por su parte trasera. Fajardo respondió que necesitaba esperar más tropas, y el gobernador partió en auxilio de la fortaleza sin la colaboración del marqués.

Viendo la actitud de Maza, el marqués lo detuvo diciéndole que el día siguiente partirían hacia Orihuela todos juntos. El gobernador decidió esperar, y D. Pedro Fajardo cumplió su palabra ".

El 29 de agosto, el ejército real al completo partió de Monteagudo en formación de batalla con la misión, no ya de socorrer a Jaime Despuig, sino de «borrar para siempre el triste nombre de Germanía». El contingente militar, estaba dirigido por Maza y Fajardo, contaba con la participación de los principales nobles del Reino de Murcia y de otros de la Corona aragonesa como el marqués de Elche o el Almirante de Aragón, y estaba conformado por 200 hombres a caballo y 6.000 infantes, todos bien resguardados por una poderosa artillería de campaña y gruesos cañones ${ }^{21}$.

El día siguiente, 30 de agosto, el ejército marchó hacia Orihuela. Y en el llamado Rincón de Bonanza, «extrañamente pintoresco por el contraste de la sierra patética y el florido tapiz de verdura», se celebró la batalla decisiva. Las tropas de D. Pedro Maza y el marqués de los Vélez consiguieron una victoria aplastante. Y el triunfo del bando real-nobiliario, además de permitir el control de Orihuela, sirvió para atajar el evidente peligro que existía de que las Germanías valencianas y las Comunidades castellanas se fundiesen, y las revueltas adquirieran el rango de una verdadera revolución civil ${ }^{21}$.

Más de 3.000 componentes de las milicias agermanadas perecieron en el campo de batalla, o ahogados en las turbias aguas del río Segura y de sus azarbes. No obstante, una vez se decidió el enfrentamiento en favor del ejército dirigido por los dos nobles mencionados, la mayor parte de los insurrectos -y entre ellos, su líder, Pedro Palomares- huyó en todas las direcciones. Temiendo las represalias, también se dieron a la fuga muchos de los partidarios de la revuelta que se habían quedado en Orihuela, de modo que la ciudad quedó semidesierta ${ }^{22}$.

18. Hidem, pp. 79-80.

19. Ibidem, pp. 81-86.

20. Hident, pp. $87-88$.

21. Ibidem, pp. $88-89$.

22. A.M.O. Libro $n^{\circ} 2208$, Libro de Procedimientos, 1434-1525, ff. 90v., 92, 98v., 104-104v., $11 \mathrm{v}$. 
Entonces, el marqués de los Vélez, «atrobantse poderos», decidió entrar en la ciudad con sus tropas e iniciar su saqueo ${ }^{23}$.

Cuando D. Pedro Maza y los oficiales reales que le acompañaban comprendieron las "grans vexacions $i$ violencies» que el marqués tenía la intención de perpetrar y consentir, le pidieron que «no permetes tanta destruccio», en una ciudad "que es del Rey». Pero D. Pedro Fajardo desoyó tales indicaciones y dio vía libre a sus hombres ${ }^{24}$.

La rapiña duró 30 días, hasta el 29 de septiembre, y según la opinión de los propios oriolanos que la vivieron y la sufrieron, fue «lo mes cruel saquo que a ciutat ni a part neguna fins a huy ses donat». Alicientes, desde luego, no les faltaron a los murcianos para actuar con tal saña si tenemos en cuenta el odio que sentían hacia los habitantes de la ciudad del Bajo Segura; una «malicia» que se había acentuado especialmente durante los últimos quince años a causa de las diferentes incidencias del Pleito del Obispado. Este preciso factor, si hacemos caso a un testimonio directo, fue el que más motivó a los hombres de Fajardo. Un testigo presencial de los hechos, llamado Bartolomé Togores, escuchó «dir a molts dels castellans que ab lo dit marques venien, que no venien per desfer la dita germania, sino per la enemiga del bisbat y plet de Murcia ab Oriolas ${ }^{25}$.

A su entrada, las tropas murcianas no hallaron ninguna oposición. Como adelantamos, casi toda la población, que se había declarado abiertamente por la Germanía, había huido de la ciudad para escapar de las represalias. D. Pedro Maza había ordenado que detendría, ahorcaría y descuartizaría a cuantos agermanados hallase portando armas, y la mayoría de los afectos a la Unión no quisieron aguardar la llegada del gobernador y salieron de la ciudad. Muy pocos fueron los «populars» que se quedaron en ella, y durante el mes que duró el Saco permanecieron escondidos «en algunes cases», y no se atrevieron a mostrarse en público «per temor de la justicia, per lo gran delicte que havien comes», ni a «comparer, perque nols prenguessen y penjassen». De esta forma, únicamente quedaron «visibles» los caballeros y ciudadanos honrados que llegaron a la ciudad con D. Pedro Maza, y que habían participado activamente en su recuperación bélica. Y entre que los agermanados eran pocos y estaban «amedrentats de por», «indeffensos», «desarmats y destrosats», los caballeros y ciudadanos eran aún menos que éstos, y los murcianos los superaban a todos ellos «de vint parts la una», nadie, ni siquiera el propio gobernador Maza, pudo evitar el desastre y el caos ${ }^{26}$.

Además, la actitud represiva de D. Pedro imposibilitó aún más el entendimiento entre las dos fuerzas oriolanas, pues 35 de los rebeldes que permanecieron dentro de

23. Hemos hallado múltiples datos acerca del Saco gracias a un proceso informativo que recibió durante los meses de abril y mayo de 1525 el lugarteniente del gobernador, D. Luis Togores, a instancias de Bernardo Manresa, procurador del capítulo, el clero y la ciudad de Orihuela, y su diócesis, con la intención de que nadie pudiese olvidar la crueldad con que actuaron el marqués de los Vélez y sus hombres. Hemos localizado dos copias de dicho expediente. Una en el A.M.O. Libro $n^{\circ} 2208$, Libro de Procedinienos, 1434-1525, ff. 88-169. Y otra en el A.C.O. Armario X, libro n' 1094, ff. 133-222. En adelante, haremos alusión a la primera de las copias a la hora de ofrecer las referencias documentales.

24. A.M.O. Libro $n^{\circ} 2208$, Libro de Procedimientos, 1434-1525, ff. 92, 99.

25. Ibidem, ff. $92.111 \mathrm{v}$

26. Ibidem, ff. 92, 98v., 102v.. 103, 111v., 148v., 149v., 153-153v. 
Orihuela fueron «pressos per justicia» y ejecutados públicamente en la horca, y descuartizados post mortem. Entre el amplio grupo de «penjats y desquarterats» figuró el líder del movimiento, Pedro Palomares, quien tras su huida fue capturado en Lorca y llevado a Orihuela, donde, como hemos dicho, halló la muerte ${ }^{27}$.

Así, ante la inexistencia total de oposición efectiva, los murcianos pudieron actuar con plena libertad e impunidad. Y saquearon todo lo saqueable tanto dentro de las casas de los vecinos seglares de la ciudad como en los diferentes recintos eclesiásticos de la misma, y no pararon hasta que no quedó nada, absolutamente nada que pudiesen acarrear. Sobre esta cuestión, hemos de destacar que las iglesias, los conventos, los monasterios y los hospitales, lejos de ser respetados reverentemente, fueron los lugares preferidos para las rapiñas. El atractivo de sus tesoros y también el morbo por los sacrilegios fueron los principales factores de tal tendencia.

Como los datos que poseemos del Saco son el fruto de diferentes testimonios presenciales, y no tienen un sentido cronológico, a continuación, nos disponemos a analizar las diferentes tropelías cometidas por los agresores según una distinción entre rapiñas a propietarios laicos y saqueos a instituciones religiosas.

Entre las primeras, los principales objetivos fueron las armas, la ropa, el trigo, las bestias - «axi de laurada com altres»-, los libros, e incluso los cautivos que tenían los habitantes de la ciudad. No obstante, el afán por saquear no se quedó únicamente en tales apetecibles ítems, sino que fue mucho más allá. Cuando faltaron los arriba señalados, «no tenint ja que saquejar», los murcianos robaron «los claus de les parets», y también «les portes de les cases y finestres» (para llevarse las «tancadures y ferrollats») ${ }^{2 s}$.

Por otra parte, los expoliadores comenzaron sus hurtos por las casas de los agermanados, pero pronto sus miradas se dirigieron hacia las más ricas residencias de los caballeros y nobles. Al surgir los primeros incidentes, sus propietarios se quejaron al gobernador Maza para que les diese su protección. D. Pedro se dirigió a los saqueadores, conminándoles a que dejasen intactos los edificios señoriales, pero éstos despreciaron su autoridad y le respondieron secamente que «nol conexien nel volien obehir», pues sólo acataban las órdenes del marqués y éste no les había hecho ninguna excepción. $Y$ de esta manera, ninguna casa se libró del ataque «dels castellans» "'.

Por último, hemos de comentar que el propio D. Pedro Fajardo participó en el Saco, puesto que decidió robar la artilleria defensiva de la ciudad -«una culebrina de bronzo e altres tirs de bronzo»-, "la vandera e pendo» de la misma -que estaba guardada, según la costumbre local, en la casa del justicia-, y también un buen número de banderines que había en las capillas de las diferentes iglesias de la población, y que algunos caballeros solían dejar sobre sus sepulturas para que se tuviese memoria de ellos ${ }^{30}$.

27. Ibidem, ff. $111 \mathrm{v} .$, 146-146v. CHIARRI MARTÍN, M.L., op. cit., p. 95.

28. A.M.O. Libro n 2208, Libro de Procedimientos, 1434-1525, fif. 92, 103-103v., 129, 144-144v.

29. Hidem, if. $93-93 v, 98 v-99$.

30. Ibiden, ff. 93-93v., 104, 127, 130v. El marqués expuso todas las banderas hurtadas en su capilla de la Catedral de Murcia. 
En cuanto al saco de establecimientos eclesiásticos, hemos de destacar que a los expoliadores no les refrenó el temor a Dios y al posible castigo divino que el Señor les pudiese infligir. Eran conscientes de que las iglesias o los conventos eran lugares ricos en objetos de valor, y poco les importó su carácter sagrado. Además, pronto descubieron que muchos agermanados, confiando en que los murcianos -católicos como ellos- respetarían las propiedades de la Iglesia, o simplemente como última y única solución para evitar la pérdida de sus bienes, habían escondido sus posesiones más preciadas (vestiduras más o menos lujosas, joyas) en dichos recintos, y se dedicaron a buscarlos por los más recónditos rincones o en los lugares más insospechados, y a la vez más dignos de respeto. Así, aunque en un principio guardaron algo las formas -se dedicaron a buscar dentro de los cojines y colchones que había en las iglesias-, posteriormente, «ab molta poca reverencia, e desacat e menyspreu», se exacerbaron en su afán por robar, llegaron a abrir tumbas «per veure si havia algunes coses que saquejar dins aquelles», e incluso arribaron al extremo de romper imágenes de Cristo, la Virgen o los santos, para comprobar si en su interior estaban escondidos los tesoros del pueblo oriolano ${ }^{31}$.

Esa misma falta de escrúpulos espirituales también se manifestó en el tipo de objetos que fueron hurtados. Hemos de señalar de esa larga lista «calsers, patenes, creus y altres reliquies», "draps de confraries, de enterrar los morts», todo tipo de ornamentos, e incluso las vestimentas de los santos que estaban en los altares, a los cuales desnudaron por completo sin sentir ningún pudor ${ }^{32}$. Y aún más, «ab molta superbia» y con las armas que portaban, no dudaron en romper «los rexats de ferro» que impedían el paso a las capillas, con la intención de abrir los armarios y los sagrarios, y llevarse «los cofrenets e reliquiaris a hon lo Sagrat Cors de nostre Senyor thesu Christ estava, e les crismeres», "derramant per terra lo oli de la extrema uncio e part de les formes consagrades ${ }^{33 .}$ Como podemos apreciar, el morbo que sentían los saqueadores por cometer sacrilegios es un hecho irrefutable.

El marqués de los Vélez tuvo, asimismo, una participación activá en el saco de establecimientos religiosos. Diferentes testimonios coinciden en señalar que D. Pedro Fajardo, conociendo «les injuries e inrreverencies, robos y altres leigs y mals actes» que sus hombres estaban perpetrando en dichos sacros recintos, no quiso reprenderles ni prohibir tales actividades, sino que para darles más «animo y audacia», entró en las iglesias montado a caballo y acompañado por mucha "gent armada», y les mandó que expoliasen cuanto pudiesen. Y mientras tanto sus hombres seguían hurtando en su presencia, él se dedicaba a pasear por sus naves, convirtiéndolas en «femer y stable»-estercolero y establo-, y a recomendarles que pusiesen sus respectivos botines «en carretes» y se los llevaran. Sin embargo, no sólo se dedicó a la contemplación de los actos delictivos, sino que también intervino en algunos de ellos. Por ejemplo, conocemos que usi algunes persones ploraven y donaven crits, y temien de la sua roba, perque no les hi llevassen, lavors lo dit marques los menaçava, yls hi feu

31. Ibidem, ff. $92 \mathrm{v},, 103 \mathrm{v}-104,108 \mathrm{v}$.

32. Ibidem, ff. 92, 103-103v., 129-129v.

33. Ibidem, ff. $92 \vee ., 103-103 v ., 112$. 
llevar, y si no volien donarla de sa voluntat, los hi fea donar per força y ab amenaces, y encara pegantlos» ${ }^{34}$.

Su labor en la dirección del saco de instituciones eclesiásticas es indiscutible ya que él mismo, sin respetar «la honor de les sglesies y monestirs y del Corpus Sagrat», perseverando en «sa malicia y mala voluntat» y «no tement a Deu», ordenó su expolio, e incluso se encargó de repartir las tres parroquias en que estaba dividida la ciudad entre los capitanes de su ejército. A Melgarejo, el capitán de Mula, le asignó la iglesia de las Santas Justa y Rufina. A Pedro Carrillo, de Murcia, le concedió la de Santiago. Y consciente de que la Colegiata era mucho más rica que las otras dos iglesias, dividió su saqueo entre murcianos y lorquinos, de modo que a Carrillo le concedió «el cors de la dita seu y capelles de aquella», y al capitán Teruel, de Lorca, le concedió la «cambra y sala de capitol ${ }^{35}$.

El expolio de la Colegial fue seguido muy de cerca por el marqués de los Vélez. Al igual que hizo en las otras iglesias de la ciudad, entró a caballo en la del Salvador, acompañado por otros secuaces, y estuvo paseando por sus naves mientras se producían los hurtos. Así, por la presencia de «cavalls» y «rocins», el sacro recinto se convirtió en un establo, y quedó lleno de porquería, defecaciones, «y altres brutees moltes». El marqués vio impasible cómo sus hombres «despenjaven les cortines y draps de dita sglesia, y les tovalles dels altars y faristors de ferro de dita Seu». Además, cuando le requirieron «favor y ajuda», gustoso se la ofreció. Y se mostró tan cruel o más que sus soldados cuando un hombre al que le habían robado toda la ropa, se le acercó para pedirle clemencia, y «a cavall com stava», le respondió pegándole «dos o tres bastonades» ${ }^{30}$.

Sobre el transcurso del saco del Salvador, hemos de destacar principalmente los actos que tuvieron lugar en la capilla del Corpus ${ }^{37}$. Los soldados de Fajardo, no estando aún satisfechos con los «crims, delictes y heretgies» que habían cometido, «ajustant crim a crims y heretgia a heretgies, en gran menyspreu de Nostre Senyor Deu e de la nostra fe e religio christiana», «y encara per molt mes mostrar la enemiga y mala voluntat que contra los de dita ciutat y sglesia» tenían, cogieron «molta broça, fem e altres brutedats»-deshechos, estiércol y otras porquerías- y las tiraron en dicho lugar, «que mes semblava femer que capella». Y acto seguido, abrieron su sagrario «ab destrals y armes», tomaron «deu o onze formes consagrades del Corpus precios de Ihesuchrist», las rompieron e hicieron trozos, y las lanzaron al suelo, pisoteándolas, pateándolas y revolviéndolas entre la basura.

Asistió al denigrante suceso, el sacristán mayor de dicha iglesia, Pedro Santander, quien solicitó a un notario que diese fe en un auto público de cuanto había acontecido. Después, le hizo presentar tal instrumento al provisor de Cartagena, D. Juan Ruiz de Salvatierra -quien, para más inri, también era inquisidor del Reino de Murcia

34. Ibidem, ff. 93, 103v.-104, 130.

35. Ibidem, ff. $92-92 \mathrm{v} ., 114 \mathrm{v} ., 117 \mathrm{v} .-118$ y $157 \mathrm{v}$.

36. Lbidem, ff. 106v., 109, 118, 139v., 158.

37. Hay abundante información sobre estos hechos en ibidem, ff. 92v.-93, 109, 129v., 120v.-121, 139$139 \mathrm{v}, 157 \mathrm{v},-158$. 
y la Gobernación de Orihuela-, que estaba en la ciudad del Bajo Segura, y el licenciado "ho passa per alt hi feu molt poca mencio ni diligencia».

Cuando los hombres del marqués terminaron de divertirse con tan sacrílega práctica, algunos clérigos se pusieron a recoger del suelo las afrentadas hostias. No obstante, fueron descubiertos por «los dits soldats y altres gents que per alli entraven», y acabaron de la misma forma que las formas consagradas, rebozados de estiércol. Y fueron maltratados hasta que desistieron de recogerlas, y tuvieron que dejarlas en tan irreverente exposición.

Sin embargo, el primer fracaso no mudó las intenciones de los eclesiásticos del Salvador, quienes deseaban con todas sus fuerzas librar a su divino patrón de tan ignominiosa situación. Por ello, después de unos cuantos días, una noche, Luis de Soler, Pedro Santander y otros valerosos clérigos, alumbrados por «antorches enceses» y por una luminaria que había en dicha capilla, recogieron del suelo los trozos de pan eucarístico con toda la «veneracio» que pudieron, y los volvieron a colocar dentro del sagrario. Y entonces ocurrió un milagro... La citada luminaria, que había estado ardiendo desde que las hostias fueron tiradas al piso de la estancia, se apagó. Entonces, los eclesiásticos intentaron volver a encenderla, y se dieron cuenta de que estaba absolutamente «sequa e sens oli nengu». Y pese a que volvieron a ponerle combustible, la vela no volvió a arder. Enfervorecidos por el prodigio, llamaron de inmediato al notario Bernardo Manresa, y éste comprobó la circunstancia de la luminaria, y dio fe pública del portento sacro.

Por otra parte, no fueron únicamente los murcianos los que cometieron excesos o abusos. Aprovechando el caos de la situación, uno de los virtuosos clérigos que fueron con Luis de Soler a recoger las formas maltratadas, se quedó con algunas hostias, y convidó a tomar una de ellas a un fraile del monasterio de la Virgen María de la Merced. Y no fue el único caso de este tipo que se dio, pues testigos como el mercedario Pedro Rocamora afirmaron que por aquellas fechas se decía por la ciudad que tales prácticas ilícitas se repitieron en otras iglesias ${ }^{38}$.

En el mencionado monasterio de la Merced también tuvieron lugar incidentes de consideración, pues sus frailes trataron de estorbar las rapiñas murcianas, pese a su evidente inferioridad.

Un ejemplo de ello lo hallamos en el comportamiento de Nicasio Olivares, antiguo comendador de la citada casa regular, quien descubrió a algunos soldados robando en la sacristía los corporales sagrados. Olivares vio cómo se los colocaban en el cuello como si fuesen pañuelos y no pudo resistirse a decirles:- «Fills meus, per que feu axo? Veu que aquexos draps que levau al coll son los corporals. Dexau-los a la sglesia y nols tracteu tant yrreverentment». Y los soldados simplemente lo pisotearon ${ }^{39}$.

El marqués de los Vélez también tuvo cierto protagonismo en el saqueo de este monasterio. Según su costumbre, entró en él sobre su caballo, acompañado por «molta gent armada», y estuvo inspeccionando los expolios. Y mientras paseaba por la

38. Ibidem, ff. 126-126v., 129v., 132v.

39. Ibidem, ff. 131 v.-132. Los corporales son los lienzos que se extienden en el altar, encima del ará, para poner sobre ellos la hostia y el cáliz. 
iglesia, un soldado llamado Martín Ferrández de Tuesta trató de arrebatarle a «una persona miserable» una prenda de lino que constituía su única vestimenta. Ofuscado por la mezquindad del murciano, intervino un fraile llamado Pedro Gómez para defender al pobre. El ladrón amenazó al mercedario, pero éste no pareció inmutarse. Por ello. Ferrández acudió al marqués para pedirle ayuda. Acto seguido, Fajardo se acercó a Gómez y al indigente, y le requirió al primero que no embarazase la labor de su prosélito. Y para su sorpresa, el fraile, enrabietado, se acercó con el pie el trozo de tela disputado, que había acabado en el suelo, y, demostrando cierta habilidad, lo pateó hacia «una sepultura e vas» en el que solían ser enterrados los religiosos del monasterio, y acertó a introducirlo en ella. El acto irritó tanto al marqués que, sin pensárselo un ápice, echó mano de su lanza e intentó golpear al fraile. Éste evitó la lanzada y atacó al noble con la pica que llevaba para defenderse. El experimentado marqués esquivó la acometida del mercedario y le volvió a atacar. Pero Gómez, «prest y lauger» se metió por una portezuela que daba al claustro del monasterio y con inusitada facilidad consiguió escapar de la ira del de los Vélez. Y escondido, pudo oír como el marqués les decía claramente a sus hombres que fuesen a saquear la iglesia y el convento de San Juan, que estaba habitado por monjas clarisas, arengándoles además con tales palabras: - «aquead bien vosotros ahora porque otro dia se hara lo mismo a voso$\operatorname{tros} \otimes^{\text {+11. }}$.

Y los soldados siguieron a la perfección el consejo de su líder. Tras oír tal indicación, se dirigieron a la imagen de la Virgen de Montserrat, que estaba en la iglesia de ese mismo monasterio, le robaron los ornamentos, la desnudaron, y se llevaron su corona. $Y$ cuando ya no les quedó nada que expoliar, en su afán por hallar objetos ocultos, cometieron dos nuevas fechorías de significación. «Postposada la temor de Nostre Senyor Deu y de la sua real y divinal justicia, y en gran vilipendi y desacat de la semblança de aquell», los soldados se acercaron a un Crucificado hueco que había en una capilla de dicha iglesia, y le rompieron las dos piernas y un brazo para ver si en su interior «hi havia alguna cosa-reliquies, or o argent-per a saquejar». Y a continuación, desenfrenada su ambición, llegaron a desenterrar el cuerpo de un zapatero "que pochs dies havia hera mort», creyendo que en la sepultura había escondidos objetos de valor, y como no hallaron nada más que los restos del difunto, se fueron sin volverlo a enterrar ${ }^{41}$.

Conocemos pocos detalles sobre el saco de la parroquial de Santiago. Únicamente tenemos noticia del enorme desconsuelo con el que se quedaron sus presbíteros, y de que los soldados murcianos se llevaron absolutamente todo lo que pudieron acarrear. Y que tal como sucedió en la iglesia del Salvador, también fue objeto de hurto su sagrario, del que desaparecieron «lo reliquiari y cofrenet de argent» que contenía las formas consagradas, $\mathrm{y}$ «les crismeres de argent que dins lo dit almari heren» ${ }^{+2}$.

No obstante, los incidentes más graves acaecieron en el Hospital de San Bartolomé, en el que los saqueadores hicieron demostración de su máxima crueldad. A conti-

40. Ibidem, IT. 126v., 132v., 134-134v.

41. Ibidem, 1T. 126v.-127, 130-130v., 139v.

42. Hidem, 代. 142v-143. 
nuación, reproducimos literalmente tres frases del testimonio de Vicente Martí que, por la gravedad de los hechos a los que se refieren, no requieren ningún comentario adicional:

"Los soldats del dit exercit saquejaren lo spital de senyor Sent Berthomeu de la present ciutat de Oriola, que no dexaren cosa nenguna en aquell, que fins lo calzer y patena y ornaments y vestiments de dita sglesia robaren y saquejaren».

«Los dits soldats, los pobres que en lo dit spital trobaren malalts y gitats en los llits, los langaven dels lits en terra, y prenien y saquejaven les robes de aquells y dels llits hon aquells staven, als quals pobres dexaren stesos, malalts, en terra, cosa que turchs e infeels de nostra sancta fe catholica non agueren feyt».

«Los dits soldats trobaren a un home quis deha el Portugues mort y mortallat per a quel volien soterrar, y los dits soldats li llevaren y saquejaren la mortalla en que stava mortallat yl dexaren nu en carns en terra, ab molt poca temor de Nostre Senyor Deu y de sa divinal justicias ${ }^{43}$.

Una vez terminado el relato de toda esta serie de tropelías, hemos de resaltar que el Saco también conllevó funestas consecuencias para los intereses episcopales oriolanos. Recordemos que pese a haber realizado dos intentonas y a contar con el favor real y el auxilio del brazo secular, el cabildo de Cartagena aún no había conseguido poner en ejecución el breve revocatorio de la creación del obispado de Orihuela, y el clero y el pueblo de la ciudad del Bajo Segura seguían negándose a someterse a su obediencia y jurisdicción. Por ello, la intervención del marqués de los Vélez les brindó la ocasión propicia para «la vuelta a la normalidad», a la situación anterior a la expedición de las bulas del 13 de mayo de 1510. Y a él acudieron para conseguir tal objetivo.

D. Pedro Fajardo atendió el requerimiento, y logró «convencer» a Jos oriolanos para que reconociesen la autoridad del obispo Mateo y del cabildo de Cartagena. Empero, sus métodos, como veremos, no fueron nada ortodoxos...

El 4 de septiembre, tras departir en su residencia con el provisor Salvatierra y otros canónigos y clérigos del cabildo de Cartagena, a los que tenía alojados ${ }^{4-1}$, decidió reunir un numeroso contingente formado por «molta gent a cavall e de peu armada», y «a usança de guerra», «ab son standart e senya davant ell», se dirigió a caballo hacia la plaza de la ciudad. Llegó «al canto de la Lonja», y allí, "a son de tronpeta», convocó a los que en las cercanías se hallaban. Y cuando estuvo rodeado por un buen número de oriolanos, mandó pregonar un bando, por el que ordenó tanto a seglares como a eclesiásticos que en el término de las seis horas siguientes diesen «la possessio e obediencia» al obispo Mateo y al cabildo de Cartagena, que renunciasen a todos sus derechos episcopales en favor de éstos, y que, en adelante, jamás volviesen a llamar Catedral a la iglesia del Salvador, pues su única intitulación válida habría de ser la de Colegial. Y para que nadie osase contravenir su mandato, advirtió que a los

43. Ibidem,

44. Ibidem, ff. $94,147 \mathrm{v}$. 
que se le opusiesen les confiscaría todos sus bienes, les incendiaría y derruiría sus casas, y les aplicaría finalmente la pena capital ${ }^{45}$.

Después de que el voceador leyese tan duro edicto, el propio marqués intervino $\mathrm{y}$, aprovechándose de su fama de sanguinario, dirigió a la contrariada concurrencia «moltes paraules cruels y molt temeroses» a fin de causarles «molta terror y spant», pues creía que asustando a los oriolanos, éstos prestarían la obediencia con mayor diligencia. Y antes de dejar hablar a nadie, continuó su alocución afirmando que si no mostraban rápidamente su predisposición a someterse al cabildo cartaginense, «a grans e chichs» los pasaría por el filo de su espada ${ }^{46}$.

Y terminó su discurso preguntando a un gentil hombre llamado Yervens si estaba dispuesto a obedecer sus mandatos y a aceptar la superioridad murciana. El oriolano tuvo la valentía de ser sincero, y el marqués, sin dudar ni un momento, arremetió contra el gallardo, le pegó una lanzada, y lo asesinó. Y después, fríamente, dio a entender que haría matar o mataría personalmente a cuantos contradijesen sus órdenes ${ }^{47}$.

Ante el revuelo formado por el homicidio, D. Pedro Fajardo decidió acompañar a su nuncio para hacer nuevas «crides publiques». Y con su nutrida escolta y «en ardit de guerra», "ab un standart davant y ab banderes», comenzó el recorrido por las calles de la ciudad. Mandó hacer sonar «los atambors de guerra» para asustar a los vecinos y, convocándolos, les hizo comunicar su bando. Y consiguió atemorizar a toda la población, ordenando nuevos asesinatos.

Además, para que nadie pudiese escapar ni librarse de jurar la obediencia al obispo y el cabildo cartaginenses, mandó cerrar las puertas de la ciudad, y puso guardas en ellas «y en tots los lochs per hon sen podien exir y amagar, axi en la serra com en altres lochs» ${ }^{48}$.

Tras la publicación del edicto, algunos ciudadanos fueron a casa de D. Pedro Maza para comentarle las intenciones del marqués, y para pedirle que interpusiese su autoridad como gobernador del Reino de Valencia ultra Sexonam y le hiciese desistir de sus ilícitos propósitos. Pero Maza, superado por los acontecimientos, viéndose absolutamente impotente, les respondió con amargura que nada podía hacer pues el capitán general del Reino de Murcia tenía el poder en la ciudad ${ }^{49}$.

Después, se presentaron ante él otros vecinos y le preguntaron si debían dar la obediencia a los cartaginenses. Y Maza convino con las autoridades civiles y eclesiásticas que lo hiciesen, pues no les quedaba otro remedio si querían salvar sus vi-

45. En virtud de un decreto real de auxilio del brazo secular, el marqués de los Vélez únicamente tenía facultad para confiscar los bienes muebles e inmuebles de los rebeldes, y para detenerlos y encarcelarlos hasta que quisiesen prestar la obediencia. Pero de ninguna forma podía incendiar y derruir sus casas, ni mucho menos imponerles la pena capital. Al parecer, la erótica del poder y la violencia sedujo el pensamiento de D. Pedro Fajardo.

46. A.M.O. Libro ${ }^{\circ} 2208$, Libro de Procedimientos, 1434-1525, ff. 90v.-91, 93v.-94, 100, 104-104v., $112-112 \mathrm{v} ., 147-147 \mathrm{v}$

47. Ibidem, ff. $105,109 \mathrm{v},-110,127 \mathrm{v}, 140-140 \mathrm{v}, 144-144 \mathrm{v}, 147 \mathrm{v}$

48. Ibidem, ff. 94, 100-100v., 150 .

49. Ibidem, ff. 143-143v. 
das, ya que el marqués y su gente estaban dispuestos a hacer contra ellos «les majors rigors y forces del mon» ${ }^{50}$.

Y muy poco tiempo después de que se produjese esta reunión, el marqués ordenó a «alguns cavallers, gentils homens e ciutadans e capellans de dita ciutat» que se congregasen en la casa del gobernador, y una vez estuvieron allí, los amenazó de nuevo con «violencies». Hizo Ilamar al provisor Salvatierra, al maestrescuela y a otros representantes del cabildo cartaginense. $Y$ acto seguido, los referidos oriolanos les juraron obediencia y todo lo que quisieron, "per temor de la mort y de sos fills y mullers, y perque nols acabassen de destroyr cremantlos y derrocantlos les cases que les restaven, y per altres vexacions que speraven los serien fetes' "s.

Posteriormente, el marqués y los representantes del cabildo murciano se dirigieron a la iglesia del Salvador. Allí encontraron a algunos miembros del capítulo. Fajardo los hizo «seure en la Seu» y los obligó a renunciar a la creación del obispado y a aceptar la superioridad del obispo, del provisor y del citado cuerpo colegiado cartaginense. Los clérigos oriolanos no pudieron hacer absolutamente nada para oponerse a la fuerza del de los Vélez. Y los religiosos murcianos volvieron a su ciudad satisfechos por haber recuperado su prístina jurisdicción ${ }^{52}$.

Poco después, ese mismo miércoles 4, a escondidas, el justicia Juan Palomares, los jurados Juan Jiménez, Juan de Loazes, Francisco Ayora y Pedro Sanz, y el síndico de la ciudad de Orihuela, Jaime Despuig, se reunieron en el domicilio particular del noble Diego de Soler. Llamaron al notario Juan López de Tuesta, y le hicieron recibir, en nombre del pueblo de la citada ciudad y de su diócesis, una escritura de protesta y apelación contra la obediencia que acababan de jurar al obispo y el cabildo de Cartagena. En ella, relataron sucintamente los acontecimientos que habían rodeado la vuelta a la sumisión castellana, y argumentaron que ésta no podría tener ningún valor porque la habían aceptado absolutamente coaccionados y a la fuerza, y no de un modo libre y voluntario ${ }^{53}$.

Y dos días después que las autoridades civiles, el 6 de septiembre, el capítulo del Salvador, esto es, el sacristán Luis de Soler, el chantre Jaime de Soler, y los canónigos Juan Martínez, Juan Pérez Meca, Pedro Martínez, Miguel Ruiz, Jaime Gómez Daroca, Juan de Vilafranca y Luis Martínez, junto con otros beneficiados de dicha iglesia como los hebdomadarios Pedro de la Mata, Ginés Ferrández, Jaime Colmelles y Ginés Zaplana, y los presbíteros Gaspar Tafalla, Juan Ferrández, Juan Grau, Jaime Comí y Juan Ruiz, hicieron recibir al mismo notario Juan López de Tuesta una protesta de contenido muy similiar, en representación de todo el clero del obispado de Orihuela ${ }^{54}$.

50. Midem. If. 149v.-150.

51. Hidem, ff. $100 \mathrm{v}, 104 \mathrm{v}, 110,128$.

52. Hidem, f. 144.

53. A.M.O. Libro $n^{\circ} 2208$, Libro de Procedimientos, 1434-1525, ff. 79-81v. A.C.O. Armario 1, libro $n^{\circ} 1$, ff. 239-240v., y libro ${ }^{\circ} 2$, ff. $76 \mathrm{v} .-80 \mathrm{v}$. Y Armario X, libro n 1094 , ff. $128 \mathrm{v} .-130 \mathrm{v}$.

54. A.M.O. Libro $n^{\circ} 2208$, Libro de Procedimientos, 1434-1525, ff. 76-78v. A.C.O. Armario I, libro $n^{\circ} 1$, ff. 241-243, y libro $n^{\circ} 2$, ff. 71 v.-76. Y Armario X, libro n ${ }^{\circ} 1094$, ff. 126-128v. 
En fin, el Saco terminó el 29 de septiembre y, confirmando las palabras de Ricardo García Cárcel, podemos concluir el presente artículo aseverando que «ha pasado a la historia como una manifestación ejemplar del salvajismo y de la barbarie humanas» ${ }^{55}$.

55. GARCÍA CÁRCEL, R.: Las Germanías de Valencia. Barcelona, 1975, p. 125. 